This is the peer reviewed version of the following article: De Clercq, Dirk, Suhail, Aamir, Azeem, Muhammad Umer and Haq, Inam Ul (2021) Citizenship pressure and job performance : roles of citizenship fatigue and continuance commitment. Asia Pacific Journal of Human Resources, 59(3), pp. 482-505., which has been published in final form at https://doi.org/10.1111/1744-7941.12241. This article may be used for non-commercial purposes in accordance with Wiley Terms and Conditions for Use of Self-Archived Versions. 
Citizenship pressure and job performance: Roles of citizenship fatigue and continuance commitment

\section{Dirk De Clercq}

Aamir Suhail

Muhammad Umer Azeem

Inam Ul Haq

Paper accepted for publication in Asia Pacific Journal of Human Resources 


\title{
Citizenship pressure and job performance: Roles of citizenship fatigue and continuance commitment
}

\begin{abstract}
This study investigates the relationship between employees' experience of citizenship pressure and job performance, as well as the mediating role of citizenship fatigue and moderating role of continuance commitment. Multisource, time-lagged data from employees and their supervisors in Pakistan reveal that employees' beliefs that they have no other choice than to take on allegedly voluntary activities undermine their job performance, due to energy depletion evoked as citizenship fatigue. Their continuance commitment buffers this process; the indirect relationship between citizenship pressure and job performance, through citizenship fatigue, is weaker when employees believe they have limited employment alternatives, because they may perceive expectations of their citizenship as opportunities instead of threats in this case. Human resource managers thus should recognize that excessive organizational pressures for citizenship behaviors can undermine job performance, but less so among employees for whom leaving the organization appears costly.
\end{abstract}

Keywords: citizenship pressure; citizenship fatigue; job performance; continuance commitment; conservation of resources theory 


\section{Introduction}

Human resource (HR) scholars and practitioners acknowledge the need to encourage employees to go above and beyond the call of duty and undertake discretionary activities that are not part of their formal job descriptions (Ko et al. 2017; Motowidlo 2000; Rose 2016; Son and Kim 2016; Werner 2000). Such organizational citizenship behaviors (OCB), or the "good soldier syndrome" (Organ 1988), can enhance employer performance (Lin and Peng 2010) and generate positive outcomes for employees, by fueling their creative performance (He, Gu and Liu 2018) and sense of meaningfulness (Russo, Guo, and Baruch 2014), for example. Accordingly, such behaviors are highly pertinent for HR management, in line with the assertion that "the employee performance criterion should be broadened to include citizenship behaviors and contextual performance" (Bolino, Turnley, and Niehoff 2004, 243).

Yet HR management research also acknowledges that additional responsibilities can be detrimental for employees, especially if the employer places excessive emphasis on voluntary behaviors, leaving employees with the impression that they have no other choice than to allocate significant energy to voluntary efforts (Bolino et al. 2010; Culbertson and Mills 2011; Deery et al. 2017). Such pressures can manifest in different ways; for example, employees may believe that performing their formally prescribed job duties is not sufficient to achieve a reputation as a valuable organizational member, or they may sense an expectation that they sign up for extra task assignments, even if their formal job obligations leave them with insufficient time to do so (Bolino et al. 2010, 2015).

Employees' exposure to such adverse, resource-depleting work conditions, irrespective of their source, is a critical concern for HR professionals, because they can harm employees' mental well-being, work motivation, and performance (e.g., Kumarika Perera, Chew, and Nielsen 2017; Macky and Boxall 2008; Magee et al. 2017). For example, excessive work pressures might cause employees to experience frustration if they believe their employer is failing to take their personal well-being into account, by forcing them to perform activities for which they lack the energy or drive (Pooja, De Clercq, and Belausteguigoitia 2016). Although pressures to perform OCB are a pertinent form of workplace adversity, they have received relatively limited research attention in studies of employee well-being (Bolino et al. 2010) or HR management research (Deery et al. 2017; Jiao, Richards, and Hackett, 2013). The persistence of such pressures and their potential harm to organizations' employee bases indicates the need for further investigations though, 
particularly into possible negative performance consequences and ways to contain them (Bergeron 2007; Culbertson and Mills 2011).

Therefore, this study investigates how employees' experience of citizenship pressure might diminish their in-role job performance by enhancing their fatigue levels-labeled "citizenship fatigue" to emphasize the specific source of this form of depletion (Bolino et al. 2015). Citizenship fatigue is "a state in which feeling worn out, tired, or on edge is attributed to engaging in OCB” (Bolino et al. 2015, 57). Employees' continuance commitment, which stems from the difficulties employees associate with leaving their current employer because they sense limited employment alternatives, might mitigate this effect though (Meyer and Allen 1991; Veitch and Cooper-Thomas 2009; Wang 2015). Notably, the motivation that underpins continuance commitment pertains to both the cost of leaving and the instrumental benefits of staying with the current employer (Cohen 2007). Compared with affective and normative forms, which focus on psychological attachments or moral obligations that employees feel toward their employer, respectively (Gamble and Tian 2015), continuance commitment reflects employees' job security concerns, which diminish if they can adjust to their current work environment, even one that imposes significant pressures on their daily functioning (Cohen 2007; Wang 2015). Then as an outcome, this research considers employees' in-role job performance and ability to meet formally prescribed job requirements (Williams and Anderson, 1991), which is a critical determinant of performance evaluations (Bolino, Turnley, and Niehoff 2004; Takeuchi, Way, and Tian 2018). The concurrent influences of citizenship pressures and continuance commitment on job performance, through citizenship fatigue, accordingly are important considerations for HR managers.

\section{COR theory}

To substantiate the theoretical arguments, this study draws from conservation of resources (COR) theory, which asserts that employees' exposure to adverse work conditions can prompt negative performance outcomes, because they suffer resource depletion and seek to conserve any remaining resources through work-related efforts (Hobfoll 1989, 2001; Rastogi et al. 2018). The experience of citizenship pressure similarly may escalate into reduced job performance through citizenship fatigue, because of employees' tendencies to conserve resources that they otherwise would devote to performance-enhancing activities (Bergeron 2007; Bolino, Turnley, and Niehoff 2004; McCarthy, Trougakos, and Cheng 2016). As previous research 
shows, enhanced fatigue is a causal mechanism that can connect resource-draining work conditions - such as abusive supervision (Chi and Liang 2013), negative workplace gossip (Wu et al. 2018), or interpersonal problems with mentors (Yi et al. 2017) — to negative work outcomes. However, no empirical studies have investigated the potential mediating role of citizenship fatigue in relation to the harmful performance consequences of excessive citizenship pressures.

Moreover, COR theory and its underlying notion of buffering effects suggests that the harm caused by employees' exposure to workplace adversity can be mitigated if they possess personal characteristics that diminish their experience of resource losses, due to their potential to generate resource gains (Abbas et al. 2014; Hobfoll 1989). Following this logic, employees' continuance commitment may buffer against the depletion of positive energy resource reservoirs when their employer imposes undue pressures on them to do more than is prescribed by their formal job descriptions (Cates, Mathis, and Randle 2010). Employees who exhibit high levels of continuance commitment worry about their job security and actively work to comply with organizational directives to keep their jobs (Wang 2015). Employer pressures to undertake voluntary work behaviors then might represent opportunities, rather than threats, such that these employees can benefit from their organizational membership and receive positive performance evaluations if they respond positively to the pressures (Cohen 2007; Johnson and Chu-Hsiang 2006). Consistent with COR theory, energy resource losses, due to experiences of OCB pressures, might be countered by anticipated resource gains, in the form of enhanced job security, if employees comply with employer expectations to go above and beyond the call of duty (Hobfoll and Shirom 2000). Formally, when their continuance commitment is high, the positive effect of employees' experience of citizenship pressure on citizenship fatigue might be mitigated, which should have positive consequences for their job performance. ${ }^{1}$

\section{Contributions}

\footnotetext{
${ }^{1}$ This study's theoretical focus is on how continuance commitment might mitigate the relationship between citizenship pressure and citizenship fatigue, not that between citizenship fatigue and job performance. The anticipated resource gains associated with this personal resource should be especially prominent in preventing resource depletion due to excessive citizenship pressures from spilling over into the salient experience of citizenship fatigue, rather than having an impact on how employees respond to the outcome of this spillover effect-that is, when they already feel worn out or tired because of these pressures (Bolino, Turnley, and Niehoff 2004; Hobfoll and Shirom 2000).
} 
In testing these predictions, this study seeks to make several contributions to HR research. First, it applies COR theory to propose and demonstrate that employees' experience of excessive citizenship pressure in their performance appraisal can lead to lower in-role job performance because of their energy depletion, in the form of citizenship fatigue (Bolino et al. 2015; Hobfoll 1989, 2001). If voluntary behaviors are critical to employees' performance appraisal, the resulting pressures might hinder employees' ability to execute formally prescribed job tasks (Bolino, Turnley, and Niehoff 2004; Deery et al. 2017; Jiao, Richards, and Hackett 2013). Empirical studies indicate the effects of citizenship pressures on employees' actual OCB (Bolino et al. 2010), job engagement (Cates, Mathis, and Randle 2010), work-family conflict, work-leisure conflict, job stress, and turnover intentions (Bolino et al. 2010) but has only theorized about how this source of workplace adversity might undermine actual job performance (Bergeron 2007; Bolino et al. 2013). This study also extends Bolino and colleagues' (2015) application of COR theory to address the moderating role of citizenship pressure on the relationship between $\mathrm{OCB}$ and citizenship fatigue, by pinpointing the pressure to undertake OCB as a direct cause of citizenship fatigue. By investigating and unpacking the link between citizenship pressure and job performance, this research accordingly provides HR managersespecially those operating in market environments that make employees' voluntary behaviors a competitive necessity (Hodson 2002; Organ 1988; Podsakoff et al. 2000)—with critical insights into the risk of negative spillover effects. Employees may be unable to meet their in-role job requirements in the presence of excessive pressures to take on additional responsibilities, and citizenship fatigue is an unexplored mechanism by which the experience of such citizenship pressure may cause employees to underperform on their formal job duties.

Second, in response to calls to adopt contingency approaches to clarify the outcomes of excessive work pressures (e.g., Pooja, De Clercq, and Belausteguigoitia 2016), this study proposes that employees' continuance commitment may function as a buffer against the fatigue that arises with organizational pressures to go beyond formally prescribed duties, which then diminishes the likelihood that employees underperform. Consistent with COR theory, the anticipated resource gains in the form of job security offered to "good soldiers" - a critical concern for employees with high levels of continuance commitment (Devece, Palacios-Marqués, and Alguacil 2016) — can compensate for resource losses due to the experience of citizenship pressure (Hobfoll 2001). The study thus extends previous research that focuses on the negative 
features of continuance commitment, such as lower motivation levels (Meyer and Allen 1991), diminished innovative behaviors (Jafri 2010), or poor job performance (Uppal 2017). Instead, it considers continuance commitment as productive; it can mitigate the translation of citizenship pressures into enhanced citizenship fatigue. This conceptualization extends prior HR management research that focuses primarily on the direct effects of this commitment type on outcomes such as turnover intentions (Gamble and Tian 2015), early retirement (Herrbach et al. 2009), or motivations to improve (Naquin and Holton 2002). This focus on continuance commitment also expands Bolino et al.'s (2015) investigation of the buffering influences of relevant contextual factors (e.g., organizational support, team member exchange quality) on citizenship fatigue in response to OCB. With this extension, this study offers HR managers novel insights into which employees might respond less negatively to pressures to go beyond the call of duty, with beneficial consequences for their ability or motivation to meet formal performance targets (Bolino, Turnley, and Niehoff 2004; Deery et al. 2017; Werner 2000).

Third, the empirical context of this study is Pakistan, so it addresses calls for more research on the negative consequences of adverse work conditions in understudied, non-Western, and Asian settings (e.g., Peltokorpi 2018; Zhan, Li and Luo 2018). Pakistani culture is characterized by high levels of uncertainty avoidance (Hofstede, Hofstede, and Minkov 2010), so citizenship pressures and the associated energy depletion might have especially strong effects on employees' propensity to allocate less energy to performance-enhancing activities (Cates, Mathis, and Randle 2010). Moreover, the economic circumstances in Pakistan make it difficult to move from one organization to another (Rahman, Naqvi, and Ramay 2008), so employees' continuance commitment should be a particularly relevant factor. The theoretical focus on the concurrent effects of citizenship pressures and continuance commitment on citizenship fatigue and subsequent performance thus should be highly pertinent in this empirical context, as well as in other countries in the Asia-Pacific region with similar cultural profiles.

The proposed theoretical framework, with its foundation in COR theory, is summarized in Figure 1: The experience of citizenship pressures thwarts job performance because of the energy depletion resulting from these pressures. Thus, citizenship fatigue mediates between citizenship pressures and job performance. Continuance commitment then functions as a buffer, such that the translation of the experience of citizenship pressures into reduced job performance, 
through citizenship fatigue, becomes less likely when employees believe they can leverage these pressures to secure their current employment.

\section{Hypotheses}

\section{Mediating role of citizenship fatigue}

The fatigue or energy depletion caused by expectations to go beyond the call of duty may constitute an important reason that employees fail to meet in-role performance expectations (Bolino, Turnley, and Niehoff 2004; Culbertson and Mills 2011). According to COR theory, employees feel more energized and in control of their daily job tasks if they have sufficient energy resources, which they can allocate to completing those tasks (De Clercq and Belausteguigoitia 2017; Hobfoll 2001). However, when employees feel mentally or physically exhausted by undue pressures, the associated energy depletion instead may prevent them from completing their in-role job duties (McCarthy, Trougakos, and Cheng 2016). That is, the perceived requirement to take on additional responsibilities that exceed formal job descriptions can undermine employees' ability to fulfill their daily performance requirements, because they lack sufficient energy or stamina (Bolino et al. 2004). When employees feel forced to volunteer for extra assignments for which they have little time or interest, they also may be distracted by ruminations about their future in the organization (Bergeron 2007; Bolino et al. 2010). The associated drain on their energy resources may prevent them from undertaking work efforts that otherwise could help them earn positive performance evaluations (Hobfoll and Shirom 2000).

In addition to hampering their ability to meet their performance targets, the frustration that comes with feeling worn out by excessive pressures to go the extra mile may also generate negative emotions about their employer (Bolino et al. 2010; Cates, Mathis, and Randle 2010). Employees may feel offended or even angry if they experience exhaustion in response to excessive employer expectations that they should take on extra responsibilities on a "voluntary" basis (Bolino, Turnley, and Niehoff 2004; Bergeron 2007). In turn, they may lack the motivation to allocate significant energy resources to performance-enhancing activities that could contribute to their organization's success (Rayton and Yalabik 2014). Similarly, employees may interpret their own persistent fatigue, caused by excessive citizenship pressures, as a signal of their employer's lack of respect for their contributions (Bolino et al. 2015), leaving them reluctant to allocate energy to productive, performance-enhancing activities. Conversely, in the absence of unrealistic pressures to undertake voluntary activities, employees do not suffer from such mental 
or physical exhaustion, and perceptions of organizational respect for their efforts might fuel employees' willingness to help the organization (Jiao, Richards, and Hackett 2013). In short, the experience of fatigue, caused by citizenship pressures, is dysfunctional, because employees are not able or willing to execute formal job tasks successfully, to the same extent they would if such pressures were less prominent.

Hypothesis 1: Employees' citizenship fatigue mediates the relationship between their experience of citizenship pressure and job performance.

\section{Moderating role of continuance commitment}

This study predicts a buffering role of employees' continuance commitment in the indirect effect of the experience of citizenship pressure on job performance through citizenship fatigue, due to a reduced likelihood that excessive employer pressures to volunteer will escalate into mental or physical exhaustion at work. According to COR theory, employees' negative reactions to adverse resource-draining work circumstances vary with the personal characteristics they possess and that enable them to generate resource gains (Abbas et al. 2014; Hobfoll 2001). Employees' continuance commitment stems from their concerns about the negative consequences that may follow, were they to leave their employer (Johnson and Chu-Hsiang 2006; Meyer and Allen 1991). The possibility of taking on additional task assignments, particularly if strongly expected, might provide a means to mitigate these concerns (Russo, Guo, and Baruch 2014). That is, the allocation of personal energy resources to voluntary behaviors should appear particularly helpful to employees who are concerned about their job security and see instrumental value in adjusting themselves to their work environment (Wang 2015), so they regard excessive pressures to engage in citizenship behaviors as potential vehicles to gain resources (Hobfoll 2001). Conversely, employees who believe that they could easily find alternative employment may experience excessive citizenship pressures as more stressful, because they do not need to prove themselves to secure their jobs (Bolino et al. 2010).

In combination with the mediating role of citizenship fatigue, this buffering effect of continuance commitment suggests the presence of a moderated mediation effect (Preacher, Rucker, and Hayes 2007). At high levels of continuance commitment, the effect of enhanced citizenship fatigue, as a causal mechanism that explains the harmful role of resource-draining citizenship pressures for thwarting job performance, should be mitigated (Hobfoll and Shirom 2000). Formally, concerns about job security may reduce the chances that resource depletion 
stemming from citizenship pressures leads to lower job performance, through the activation of citizenship fatigue. Conversely, employees with lower continuance commitment are less concerned about their current job situation and exhibit a lower need to seek job security by going beyond the call of duty (Devece, Palacios-Marqués, and Alguacil 2016; Johnson and Chu-Hsiang 2006; Wang, 2015), so they are more likely to experience excessive pressures to take on additional responsibilities as tiring, which undermines their job performance.

Hypothesis 2: The indirect relationship between employees' experience of citizenship pressure and job performance through their citizenship fatigue is moderated by their continuance commitment, such that this indirect relationship is weaker at higher levels of continuance commitment.

\section{Method}

\section{Sample and data collection}

To test the hypotheses, data were collected from employees in several Pakistani-based organizations that operate in different sectors such as textiles, banking, and healthcare. This data collection took place in three waves, with a time lag of three weeks between each wave. These time lags were long enough to reduce concerns about recall bias and reverse causality but not long enough that significant organizational events could have occurred during the data collection. The surveys were administered in English, the official language of communication in higher education and business in Pakistan. In each survey round, the participants were told that their complete confidentiality was guaranteed, that no personal identifying information would ever be revealed, that only aggregate summary data would be made available outside the research team, and that they could withdraw as a participant at any time. The cover letters also emphasized that there were no correct or incorrect answers, that respondents would vary in their responses, and that it was essential that their answers reflect their honest opinions. These specifications diminish the likelihood of social desirability and acquiescence biases.

The first survey captured employees' experience of citizenship pressures and their continuance commitment, and the second survey assessed their citizenship fatigue. In the third survey, supervisors rated employees' job performance, which diminished common method bias concerns. Of the 400 originally administered surveys, 320 were received in the first round, 310 in the second round, and 242 surveys came from supervisors in the third round. After omitting 
surveys with incomplete data, 239 completed sets were retained for statistical analysis (60\% response rate). Of the respondents, $22 \%$ were women, and $44 \%$ had a master's degree.

Measures

The measures of the focal constructs included items from previous research, with fivepoint Likert scales ranging from 1 ("strongly disagree") to 5 ("strongly agree"). Table 1 shows the individual measurement items for each construct.

[Insert Table 1 about here].

Citizenship pressure. Employees' beliefs that their organization puts excessive pressure on them were measured with an eight-item scale developed by Bolino et al. (2010). The respondents indicated, for example, whether "There is a lot of pressure to take on additional responsibilities and volunteer for extra assignments in this organization," "My coworkers often go above and beyond the call of duty, and there is a lot of pressure for me to do so as well," and "Simply doing your formally-prescribed job duties is not enough to be seen as a good employee in this organization" (Cronbach's alpha $=.90)$.

Citizenship fatigue. The extent to which employees feel worn out because of the perceived necessity to take on responsibilities on a voluntary basis was measured with a sevenitem scale (Bolino et al. 2015). Sample items were "I feel worn out because I go beyond the call of duty for my organization," "Volunteering to take on extra tasks and assignments at work has left me feeling drained," and "Doing so much for my organization leaves me mentally or physically exhausted" (Cronbach's alpha $=.91)$.

Continuance commitment. Employees' continuance commitment was assessed with an eight-item scale that captures the extent to which they find it challenging to leave their current employment (Allen and Meyer 1990). Sample items included, "It would be very hard for me to leave my company right now, even if I wanted to," "Right now, staying with my company is a matter of necessity as much as desire," and "I feel that I have too few options to consider leaving this company" (Cronbach's alpha $=.86)$.

Job performance. To measure supervisor-rated job performance, a validated seven-item scale developed by Williams and Anderson (1991) was used. Sample items included, "This employee adequately completes assigned duties," "This employee fulfills responsibilities specified in his or her job description," and "This employee meets formal performance requirements of the job" (Cronbach's alpha $=.79)$. 
Control variables. The regression models controlled for employees' gender ( $1=$ female $)$, because female employees might be less stress-resistant than their male counterparts (Xie and Johns 1995), and this demographic trait appears in previous studies of the personal costs of exhibiting OCB (Deery et al. 2017). Other controls assessed employees' age (years), education level $(1=$ master's degree $)$, and job level $(1=$ lower, $2=$ middle, $3=$ upper $),{ }^{2}$ because employees who are older, have more education, or operate at higher levels in the organization might have greater self-efficacy and ability to cope with stressful work conditions (Bandura 1997). On average, they also likely have greater job responsibilities and workloads, which could affect their citizenship fatigue (Bolino et al. 2015).

A confirmatory factor analysis tested for validity with a four-factor measurement model. This model achieved adequate fit: $\chi^{2}(397)=667.87$, Tucker-Lewis index $(\mathrm{TLI})=.91$, confirmatory fit index $(\mathrm{CFI})=.92$, and root mean squared error of approximation $(\mathrm{RMSEA})=.05$. In support of convergent validity, the four constructs all featured highly significant factor loadings for the respective items $(p<.001){ }^{3}$ The findings also supported the presence of discriminant validity; for the six pairs generated from the four constructs, the differences in the chi-square values of constrained models (correlation between the two constructs equals 1) and their unconstrained counterparts (correlation set free to vary) were significant for each pair $\left(\Delta \chi_{(1)}^{2}>.3 .84\right)$. Additional evidence of discriminant validity is apparent from the interconstruct correlations, which are smaller than the square roots of the corresponding AVE values.

\section{Analytical techniques}

To test the hypotheses, this study relied on the Process macro for SPPS (Hayes, 2013). In addition to assessing individual paths, this approach supports comprehensive assessments of mediation and moderation effects and has been used widely for empirical tests of moderated mediation models (e.g., Wang et al. 2018). Notably, the Process macro is superior to traditional

\footnotetext{
${ }^{2}$ The lower level includes employees without any supervisory responsibilities, the middle level includes employees with some supervisory responsibilities, and the upper level includes employees who inform the organization's strategic decision making..

${ }^{3}$ The average variance extracted (AVE) values equaled .51 for citizenship pressure, .60 for citizenship fatigue, .44 for continuance commitment, and .36 for job performance. Although two values are lower than the generally recommended cut-off of .50 , such values tend to be acceptable if the corresponding composite reliabilities are higher than .70 (Huang et al. 2013), as was the case here (.86 for continuance commitment, .79 for job performance). In addition, AVE values tend to be lower in novel research contexts, such as Pakistan (Kashif, Braganca, Awang, and De Run, 2017), and the measurement items of each focal construct showed significant correlations with their respective constructs, in support of convergent validity.
} 
Sobel (1982) and Baron and Kenny (1986) tests, because it does not assume normal distribution qualities for indirect and conditionally indirect effects. Rather, it explicitly accounts for possible asymmetries in the sampling distribution by employing a bootstrapping procedure (MacKinnon, Lockwood, and Williams 2004).

First, to assess the presence of mediation (H1), the confidence interval (CI) was calculated for the indirect effect of citizenship pressure on job performance, through citizenship fatigue. This first step also assesses the signs and significance levels of the constitutive direct relationships between citizenship pressure and citizenship fatigue and between citizenship fatigue and job performance. Second, to assess the presence of moderated mediation (H2), the CIs for the conditional indirect effects were calculated. As specified in Hayes's (2013) Process macro, the CIs pertain to three different levels of the moderator: one standard deviation (SD) below its mean, at its mean, and one SD above its mean. ${ }^{4}$ In this second step, the moderating effect of continuance commitment on the relationship between citizenship pressure and citizenship fatigue was also assessed. To minimize the threat of multicollinearity, the interaction term was calculated by multiplying its corresponding mean-centered components.

Notably, the Process macro uses aggregate indicators instead of latent constructs, which resolves complex nonlinearities and associated estimation challenges that result from the need to calculate all possible product terms of the items that load on interacting latent constructs (Lattin, Carroll, and Green 2003; Marsh et al. 2013). According to Hayes, Montoya, and Rockwood $(2017,80)$, "the proper estimation of interactions between latent variables remains highly controversial, and ... the task of estimating latent variable interactions [is] so daunting that the unknown effects that can result from ignoring measurement error would seem an acceptable price to pay in exchange for the ease of the analysis and interpretation when using an observedvariable modeling tool like Process." Moreover, Ledgerwood and Shrout (2011) indicate that a latent variable-based approach is less powerful in detecting mediation effects, because of the enhanced risk of inflated standard errors. Finally, to the extent that the construct reliabilities are high and meet established criteria for acceptable reliability, any bias that might arise when

\footnotetext{
${ }^{4}$ In line with the conceptual framework, the estimated model included a moderating effect of continuance commitment on the relationship between citizenship pressure and citizenship fatigue but not between citizenship fatigue and job performance. A post hoc analysis indicated that continuance commitment did not significantly moderate the relationship between citizenship fatigue and job performance.
} 
estimating model parameters with aggregate variables, instead of latent constructs, tends to be subdued (Ledgerwood and Shrout 2011).

\section{Results}

Table 2 reports the correlation coefficients and descriptive statistics, and Table 3 provides the results generated from the Process macro. Citizenship pressure enhances citizenship fatigue $(\beta=.826, p<.001)$, which diminishes job performance $(\beta=-.208, p<.001)$. The test for mediation indicates an effect size of -.155 for the indirect relationship between citizenship pressure and job performance through citizenship fatigue; it is significant, and the CI does not include 0 [-.215, -.094], indicating the presence of mediation.

[Insert Tables 2 and 3 about here].

The test of $\mathrm{H} 2$ entailed a comparison of the strength of the conditional indirect effect of citizenship pressure on job performance through citizenship fatigue at different levels of the moderator. The results reveal diminishing effect sizes at increasing levels of continuance commitment: from -.252 at one SD below the mean, to -.169 at the mean, to -.079 at one SD above the mean (Table 4). To check for the presence of moderated mediation directly, the index of moderated mediation and its corresponding CI were also assessed. The index equals .119, and its CI does not include $0[.066,195]$. These results affirm that continuance commitment buffers against the negative indirect effect of the experience of citizenship pressure on job performance, in support of $\mathrm{H} 2$.

\section{[Insert Table 4 about here]}

Finally, the results in Table 3 indicate a negative and significant effect of the citizenship pressure $\times$ continuance commitment interaction term $(\beta=-.571, p<.001)$ in the prediction of citizenship fatigue. Figure 2 plots the effect of citizenship pressure on citizenship fatigue at high and low levels of continuance commitment. The direct positive relationship between citizenship pressure and citizenship fatigue is buffered by continuance commitment, as manifest in the diminishing effect sizes of this relationship at increasing levels of the moderator (i.e., 1.209 at one SD below the mean, .809 at the mean, .381 at one SD above the mean).

[Insert Figure 2 about here]

Even if structural equation-based approaches do not explicitly account for possible nonnormal sampling distributions of conditional effects through bootstrapping, this study still performed a robustness check with path analysis, which enabled an assessment of how well the 
conceptual model as a whole fit the data. Consistent with previous research that estimates path models with interaction effects (De Clercq, Dimov, and Thongpapanl 2013), the items of each construct were combined into a single indicator, followed by a calculation of the interaction term (citizenship pressure $\times$ continuance commitment) as the product of the respective indicators. The fit of the model was good $\left(\chi^{2}(18)=40.06, \mathrm{TLI}=.91, \mathrm{CFI}=.93, \mathrm{RMESA}=.07\right)$, and the signs and significance levels of the individual paths were consistent with those in Table $3 .^{5}$

\section{Discussion}

This study adds to previous HR scholarship by investigating how employees' experience of citizenship pressure might undermine their job performance, with a particular focus on unexplored factors that inform this process. Some investigations note the stress associated with employees' beliefs that their employer puts excessive pressure on them, which can generate negative work outcomes (Bolino et al. 2010, 2015; Cates, Mathis, and Randle 2010), but previous HR management research has not explicitly investigated how and when the associated pressures might generate negative spillover effects in the form of reduced job performance (Bolino, Turnley, and Niehoff 2004; Culbertson and Mills, 2011; Jiao, Richards, and Hackett 2013). To do so, this study has drawn on COR theory (Hobfoll 1989, 2001) to propose that (1) the inability to meet in-role performance requirements in response to the experience of citizenship pressure arises because employees feel worn out as a direct result of engaging in voluntary behaviors and (2) their continuance commitment mitigates this process.

In turn, the empirical findings provide a novel insight: Organizational pressures that force employees to take on extra assignments "voluntarily" can backfire by compromising their ability to complete their formal job duties (Bergeron 2007; Bolino, Turnley, and Niehoff 2004).

Meeting performance standards requires significant energy resources from employees (Hobfoll and Shirom 2000; McCarthy, Trougakos, and Cheng 2016). Employees who feel worn out because they perceive demands to go an extra mile and undertake tasks that are not technically part of their jobs may not possess the stamina to execute their formally prescribed job tasks too

\footnotetext{
${ }^{5}$ Following Ping (1996), the measurement error for each construct was modeled on the basis of the loadings and error variances generated from the four-factor measurement model (De Clercq, Dimov, and Thongpapanl 2013). Using composite indicators to estimate moderating effects in structural equation modeling addresses the estimation difficulties related to nonlinearity when calculating all possible product terms for items that load on the interacting constructs (Ping 1996) - which would equal $8 \times 8=64$ product terms for the citizenship pressure $\times$ continuance commitment interaction herein. Further, to reduce concerns about multicollinearity, the interaction terms reflect the product of their corresponding mean-centered components (Lattin, Carroll, and Green 2003).
} 
(Deery et al. 2017). Thus, the energy resource depletion due to the presence of citizenship fatigue, in response to excessive citizenship pressures, prevents employees from dedicating sufficient efforts to meeting their employers' performance requirements. Moreover, employees may interpret fatigue, caused by undue pressures to go above and beyond the call of duty, as disrespectful or offensive (Bolino et al. 2015), and the negative emotions they thus experience may motivate them to refrain from positive, performance-enhancing behaviors that benefit their employer (Hobfoll 2001).

This negative effect of employees' conviction that their organization expects people to take on extra responsibilities can be subdued to the extent that they perceive limited opportunities for alternative employment and are concerned about their job security (Wang 2015). According to COR theory, the resource-depleting effect of adverse work conditions is mitigated when employees possess personal features that can compensate for their resource depletion (Abbas et al. 2014; Hobfoll 2001). If employees who perceive excessive employer pressures for voluntarism are concerned about their ability to change employment, the option to take on additional responsibilities might look like an opportunity to mitigate these concerns, instead of a threat that undermines their organizational functioning (Cohen 2007). Conversely, employees with less continuance commitment have little motivation to leverage citizenship pressures as opportunities to keep their jobs (Johnson and Chu-Hsiang 2006), so they likely experience more significant resource depletion in the presence of these pressures. This buffering effect of continuance commitment is particularly insightful when considered in combination with the mediating role of citizenship fatigue. As the results pertaining to the presence of moderated mediation indicate (Preacher, Rucker, and Hayes 2007), exposure to excessive employer pressures for voluntarism translates less powerfully into lower job performance, through the fatigue stemming from such forced voluntarism, if employees exhibit higher levels of continuance commitment.

In summary, this study adds to HR scholarship by providing a more comprehensive explication of citizenship-related factors that influence job performance. Prior research alerts HR professionals that excessive pressures to go above and beyond the call of duty can compromise employees' ability to meet their formal job requirements (Bolino, Turnley, and Niehoff 2004; Culbertson and Mills 2011). Empirically, such research indicates that employees' experience of citizenship pressure can lead to increased OCB (Bolino et al. 2010) and job engagement (Cates, 
Mathis, and Randle 2010) but also citizenship fatigue (Bolino et al. 2015) and emotional exhaustion (Deery et al., 2017). Yet no HR research explicitly examines how excessive pressure to undertake OCB might undermine employees' ability to meet their in-role job requirements due to their citizenship fatigue. This study has addressed this gap by denoting how (1) the fatigue attributed to voluntary activities serves as a critical mechanism that links an important but understudied source of workplace adversity (citizenship pressure) to diminished job performance and (2) employees' continuance commitment can disrupt this process. Although the scope of the conceptual model is somewhat narrow, the research goal was to achieve depth, rather than breadth, in theorizing about why and when excessive citizenship pressures thwart job performance. The findings thereby extend previous investigations, including those in the realm of HR management, of the direct harmful effects of continuance commitment on productive work outcomes (Gamble and Tian 2015; Jafri 2010; Meyer and Allen 1991). This type of organizational commitment can have an indirect benefit, such that employees concerned about the lack of alternative employment might heed opportunities to take on additional responsibilities, even if these endeavors are not formally rewarded and feel somewhat forced. Overall, the detrimental role of stringent organizational pressures to go the extra mile, in terms of spurring fatigue and undermining job performance, can be contained by employees' beliefs that these pressures can be exploited to maintain or improve their current job situation.

\section{Limitations and future research directions}

This study has some shortcomings, which suggest research opportunities. First, it used time lags of three weeks between employees' assessments of their experience of citizenship pressure and their citizenship fatigue, as well as before the third supervisor-rated survey that assessed employees' job performance. Additional studies could use longer time frames, because the exhaustion that comes with persistent pressures to take on additional responsibilities may materialize only after extended periods of time. Moreover, the conversion of citizenship fatigue into diminished job performance might not manifest itself immediately. Longitudinal designs with longer time frames could reduce the possibility of reverse causality too; employees who adequately meet their formal performance requirements might be better positioned to find time for additional activities and therefore feel less worn out by them.

Second, this study focused on citizenship fatigue as an important explanatory mechanism for the harmful effect of citizenship pressures on job performance, but it did not explicitly 
measure the fine-grained mechanisms of this process. Exposure to excessive citizenship pressures was predicted to make employees feel worn out, reducing both their ability and their motivation to dedicate significant efforts to performance-enhancing activities. It was also expected that high levels of continuance commitment would have a mitigating effect, because the anticipated resource gains in the form of enhanced job security due to citizenship pressures might be seen as opportunities. Additional research could measure these mechanisms directly.

Third, the consideration of continuance commitment as a focal contingency factor could be complemented by investigations of other personal factors with similar impacts. For example, employees' resilience, passion for work, or creative self-efficacy may protect them from the likelihood that organizational pressures to take on extra duties "voluntarily" are perceived as tiring. Positive contextual factors also could prevent frustrations about excessive pressures from escalating into a significant depletion of personal energy reservoirs, such as perceived organizational support, fair reward systems, or transformational leadership.

Fourth, an empirical limitation of this study pertains to the consideration of only four control variables (gender, age, education, and job level) in the statistical models. Future research could consider whether these results hold even when controlling for other factors that might determine employees' responses to the hardships of OCB, such as their organizational tenure, number of hours worked per week, or negative affect (Bolino et al. 2015; Deery et al. 2017).

Fifth, relying on data from one country, Pakistan, might limit the generalizability of the findings. The theoretical arguments are country-neutral, but cultural issues could interfere. As mentioned, Pakistani culture is marked by high uncertainty avoidance, such that employees might be particularly sensitive to the uncertainty created when invitations to undertake voluntary activities are perceived as not truly voluntary and threatening to their ability to meet formal job duties (Bergeron 2007). The relative importance of continuance commitment for buffering the negative effect of the experience of citizenship pressure on job performance through enhanced citizenship fatigue in turn may be stronger than it would be in less uncertainty-sensitive countries. Cross-national studies could provide interesting insights into the relative importance of different personal factors for preventing tiring organizational expectations about voluntarism from escalating into lower job performance across different cultural contexts.

\section{Practical implications}


This study offers important implications for HR managers. Encouraging employees to engage in additional activities on a voluntary basis can be useful for both organizations and their employees, by fuelling the latter's intrinsic motivation and sense of meaningfulness, but HR professionals must take care not to force employees into such voluntarism. To the extent that voluntary work behaviors enter into employees' performance appraisals, HR managers should be aware that excessive expectations can have negative repercussions for employees' ability to meet the formal requirements of their jobs (Werner 2000). Accordingly, they might design monitoring systems to ensure that volunteering for extra assignments complements rather substitutes for employees' success in fulfilling their in-role job duties (Deery et al. 2017). Notably, the performance challenges that individual employees encounter in the presence of citizenship pressures may spill over to the organizational level and undermine the employer's competitive advantage (Bolino, Turnley, and Niehoff 2004). Thus, HR professionals should design systems to quantify whether and how invitations to go beyond the call of duty contribute to, or detract from, the organization's financial performance.

Furthermore, HR professionals should be proactive in assigning additional duties to employees with the necessary expertise and competencies (Bolino et al. 2015). They might recruit and retain employees whose abilities allow them to combine formal job duties with extra, voluntary assignments. Adequate selection systems could enable HR professionals to predict, with sufficient accuracy, which employees might be predisposed to cope with organizational pressures to work beyond their formally prescribed duties, for the good of the organization (Werner 2000). In addition, targeted training programs could "activate" these capabilities. However, if employees feel obliged to undertake voluntary activities for which they are not formally rewarded, they might miss out on certain rewards that they otherwise would receive for accomplishing regular job tasks; HR professionals should establish sufficient flexibility to adjust reward systems, such that certain work activities that previously were not compensated might become part of formal reward systems (Werner 2000).

Some employees also might be reluctant to admit that they feel stressed when their employer encourages them to go above and beyond the call of duty and volunteer for extra assignments, so as not to look weak or ungrateful for their current employment (Bergeron 2007; Bolino et al. 2010). Thus HR managers should be proactive in monitoring whether their expectations that employees take on additional responsibilities have become excessive and are 
preventing those employees from completing their regular job tasks. In particular, they should create a culture in which employees feel comfortable expressing their concerns about the work pressures they have to endure, as well as develop procedures to enable employees to share their workloads, whether formal duties or voluntary activities. In parallel, they could create specific guidelines for how employees can support one another in achieving the combined execution of their formal job tasks and extra-role activities, depending on their respective skill sets and capabilities. For example, targeted initiatives could encourage experienced employees to support newcomers' efforts to cope with citizenship pressures through one-on-one mentoring (Thomas and Lankau 2009).

This study's empirical context spans different industries, including manufacturing and services, and its findings accordingly should be generalizable to a broad variety of industry sectors. Yet HR professionals also might consider how pertinent industry factors, such as competitive intensity, determine the extent to which citizenship pressures escalate into reduced job performance. Competitive markets might increase the perceived need to go beyond the call of duty, such that employees might accept citizenship pressures more readily (Hodson 2002). But these stringent market conditions also can fuel organizational expectations that employees must take on additional responsibilities, and HR professionals should be aware of the threat of citizenship fatigue among employees in this case (Deery et al. 2017)

Accordingly, this study might be particularly pertinent for organizations in which expectations of going above and beyond the call of duty are necessitated by competitive pressures. It is up to HR professionals to create an internal environment in which employees feel motivated to perform activities for which they are not formally rewarded, by communicating that these activities are not just necessary but also provide valuable opportunities for personal development and growth that employees would not find elsewhere. Somewhat counterintuitively, employees' calculation-based, continuance commitment - typically considered a negative type of commitment in HR scholarship (Gamble and Tian 2015; Meyer and Allen 1991) — can exert positive effects and stimulate employees to comply with requests for organizational citizenship, which is in their personal interest. This is not to say that HR managers should only promote commitment resulting from employees' benefit ratios. Instead, organizations can reduce the hardships that employees encounter when they feel forced to go above and beyond the call of duty, to the extent that they attract and retain employees who embrace instrumental benefits, both 
for the organization and themselves, that result from their willingness to take on additional responsibilities and enhance the collective good, even if they are not formally compensated for those actions. 


\section{References}

Abbas, M., Raja, U., Darr, W., and Bouckenooghe, D. (2014). Combined effects of perceived politics and psychological capital on job satisfaction, turnover intentions, and performance. Journal of Management, 40, 1813-1830.

Bandura, A. (1997). Self-efficacy: The exercise of control. Freeman, New York, NY.

Baron, R.M., and Kenny, D.A. (1986). The moderator-mediator variable distinction in social psychological research: Conceptual, strategic, and statistical considerations. Journal of Personality and Social Psychology, 51, 1173-1182.

Bergeron, D.M. (2007). The potential paradox of organizational citizen-ship behavior: Good citizens at what cost? Academy of Management Review, 32, 1078-1095.

Bolino, M.C., Hsiung, H.-H., Harvey, J., and LePine, J.A. (2015). "Well, I'm tired of tryin'!" Organizational citizenship behavior and citizenship fatigue. Journal of Applied Psychology, $100,56-74$.

Bolino, M.C., Turnley, W.H., Gilstrap, J.B., and Suazo, M.M. (2010). Citizenship under pressure: What's a "good soldier" to do? Journal of Organizational Behavior, 31, 835-855.

Bolino, M.C., Turnley, W.H., and Niehoff, B.P. (2004). The other side of the story: Reexamining prevailing assumptions about organizational citizenship behaviour. Human Resource Management Review, 14, 229-246.

Cates, D.A., Mathis, C.J., and Randle, N.W. (2010). A positive perspective of citizenship pressure among working adults. Journal of Managerial Issues, 22, 330-344.

Chi, S.-C. S., and Liang, S.-G. (2013). When do subordinates' emotion-regulation strategies matter? Abusive supervision, subordinates' emotional exhaustion, and work withdrawal. Leadership Quarterly, 24, 125-137.

Cohen, A. (2007). Commitment before and after: An evaluation and reconceptualization of organizational commitment. Human Resource Management Review, 17, 336-354.

Culbertson, S.S., and Mills, M.J. (2011). Negative implications for the inclusion of citizenship performance in ratings. Human Resource Development International, 14, 23-38.

De Clercq, D., and Belausteguigoitia, I. (2017). The usefulness of tenacity in spurring problemfocused voice: The moderating roles of workplace adversity. Journal of Business and Psychology, 32, 479-493. 
De Clercq, D., Dimov, D. and Thongpapanl, N. (2013). Organizational social capital, formalization, and internal knowledge sharing in entrepreneurial orientation formation. Entrepreneurship Theory and Practice, 37, 505-537.

Deery, S., Rayton, B., Walsh, J., and Kinnie, N. (2017). The costs of exhibiting organizational citizenship behavior. Human Resource Management, 56, 1039-1049.

Devece, C., Palacios-Marqués, D., and Alguacil, M.P. (2016). Organizational commitment and its effects on organizational citizenship behavior in a high-unemployment environment. Journal of Business Research, 69, 1857-1861.

Gamble, J., and Tian, A.W. (2015). Intra-national variation in organizational commitment: evidence from the Chinese context. The International Journal of Human Resource Management, 26, 948-970.

Hayes, A.F. (2013). Introduction to mediation, moderation, and conditional process analysis: A regression-based approach. New York: Guilford Press.

Hayes, A.F., Montoya, A.K., and Rockwood, N.J. (2017). The analysis of mechanisms and their contingencies: PROCESS versus structural equation modeling. Australasian Marketing Journal, 25, 76-81.

He, C., Gu, J., and Liu, H. (2018). How do department high-performance work systems affect creative performance? A cross-level approach. Asia Pacific Journal of Human Resources, 56, $402-426$.

Herrbach, O., Mignonac, K., Vandenberghe, C., and Negrini, A. (2009). Perceived HRM practices, organizational commitment, and voluntary early retirement among late-career managers. Human Resource Management, 48, 895-915.

Hobfoll, S.E. (1989). Conservation of resources. A new attempt at conceptualizing stress. American Psychologist, 44, 513-524.

Hobfoll, S.E. (2001). The influence of culture, community, and the nested-self in the stress process: Advancing conservation of resource theory. Applied Psychology: An International Review, 50, 337-369.

Hobfoll, S.E., and Shirom, A. (2000). Conservation of resources theory: Applications to stress and management in the workplace. In R.T. Golembiewski (Ed.), Handbook of organization behavior ( $2^{\text {nd }}$ ed., pp. 57-81). New York: Dekker. 
Hodson, R. (2002). Management citizenship behavior and its consequences. Work and Occupations, 29, 64-96.

Hofstede, G.H., Hofstede, G.J., and Minkov, M. (2010). Cultures and organizations: Software of the mind. Intercultural cooperation and its importance for survival ( $3^{\text {rd }}$ ed.). New York: McGraw-Hill.

Huang, C.-C., Wang, Y.-M., Wu, T.-W., and Wang, P.-A. (2013). An empirical analysis of the antecedents and performance consequences of using the moodle platform, International Journal of Information and Education Technology, 3, 217-221.

Jafri, M.H. (2010). Organizational commitment and employee's innovative behavior: A study in retail sector. Journal of Management Research, 10, 62-68.

Jiao, C., Richards, D.A., and Hackett, R.D. (2013). Organizational citizenship behavior and role breadth: A meta-analytic and cross-cultural analysis. Human Resource Management, 52, $697-714$.

Johnson, R.E., and Chu-Hsiang, C. (2006). "I" is to continuance as "We" is to affective: the relevance of the self-concept for organizational commitment. Journal of Organizational Behavior, 27, 549-570.

Kashif, M., Braganca, E., Awang, Z., and De Run, E.C. (2017). You abuse but I will stay: The combined effects of job stress, customer abuse, and emotional intelligence on employee turnover. Journal of Management Development, 36, 899-914.

Ko, C., Ma, J., Kang, M., English, A.S., and Haney, M.H. (2017). How ethical leadership cultivates healthy guanxi to enhance OCB in China. Asia Pacific Journal of Human Resources, 55, $408-429$.

Kumarika Perera, H., Chew, E.Y.T., and Nielsen, I. (2017). A psychological contract perspective of expatriate failure. Human Resource Management, 56, 479-499.

Lattin, J.M., Carroll, J.D., and Green, P.E. (2003). Analyzing multivariate data. Belmont, CA: Thomson Brooks/Cole.

Ledgerwood, A., and Shrout, P. E. (2011). The trade-off between accuracy and precision in latent variable models of mediation processes. Journal of Personality and Social Psychology, $101,1174-1188$. 
Lin, C.-C., and Peng, T.-K. (2010). From organizational citizenship behaviour to team performance: The mediation of group cohesion and collective efficacy. Management and Organization Review, 6, 55-75.

MacKinnon, D.P., Lockwood, C.M., and Williams, J. (2004). Confidence limits for the indirect effect: Distribution of the product and resampling methods. Multivariate Behavioral Research, 39, 99-128.

Macky, K., and Boxall, P. (2008). High-involvement work processes, work intensification and employee well-being: A study of New Zealand worker experiences. Asia Pacific Journal of Human Resources, 46, 38-55.

Magee, C., Gordon, R., Robinson, L., Caputi, P., and Oades, L. (2017). Workplace bullying and absenteeism: The mediating roles of poor health and work engagement. Human Resource Management Journal, 27, 319-334.

Marsh, H.W., Wen, Z., Hau, K., and Nagengast, B. (2013). Structural equation models of latent interactions and quadratic effects. In: Hancock, G.R., Mueller, R.O. (Eds.), A second course in structural equation modeling, $2^{\text {nd }}$ ed., Information Age: Greenwich, CT.

McCarthy, J.M., Trougakos, J.P., and Cheng, B.H. (2016). Are anxious workers less productive workers? It depends on the quality of social exchange. Journal of Applied Psychology, 101, 279-291.

Meyer, J. P. and Allen, N. J. (1991). A three-component conceptualization of organizational commitment. Human Resource Management Review, 1, 61-89.

Motowidlo, S.J. (2000). Some basic issues related to contextual performance and organizational citizenship behavior in human resource management. Human Resource Management Review, $10,115-126$.

Naquin, S.S., and Holton, E.F, III (2002). The effects of personality, affectivity, and work commitment on motivation to improve work through learning. Human Resource Development Quarterly, 13, 357-376.

Organ, D.W. (1988). Organizational citizenship behavior: The good soldier syndrome. Lexington Books, Lexington, MA.

Peltokorpi, V. (2018). Abusive supervision and emotional exhaustion: the moderating role of power distance orientation and the mediating role of interaction avoidance. Asia Pacific Journal of Human Resources, doi:10.1111/1744-7941.12188 
Ping. R.A. (1996). Latent variable interaction and quadratic effect estimation: A two-step technique using structural equation analysis. Psychological Bulletin, 119, 166-175.

Pinto, M.B., Pinto, J.K., \& Prescott, J.E. (1993). Antecedents and consequences of project team

Podsakoff, P. M., MacKenzie, S. B., Paine, J. B., and Bachrach, D. G. (2000). Organizational citizenship behaviors: A critical review of the theoretical and empirical literature and suggestions for future research. Journal of Management, 26, 513-563.

Pooja, A.A., De Clercq, D., and Belausteguigoitia, I. (2016). Job stressors and organizational citizenship behavior: The roles of organizational commitment and social interaction. Human Resource Development Quarterly, 27, 373-405.

Preacher, K.J., Rucker, D.D., and Hayes, A.F. (2007). Assessing moderated mediation hypotheses: Theory, methods, and prescriptions, Multivariate Behavioral Research, 42, 185227.

Rahman, A., Naqvi, S.M.M.R., and Ramay, M.I. (2008). Measuring turnover intention: A study of IT professionals in Pakistan. International Review of Business Research Papers, 45-55

Rastogi A., Pati, S.P., Krishnan, T.N., and Krishnan S. (2018). Causes, contingencies, and consequences of disengagement at work: An integrative literature review. Human Resource Development Review, 17, 62-94.

Rayton, B.A., and Yalabik, Z.Y. (2014). Work engagement, psychological contract breach and job satisfaction. International Journal of Human Resource Management, 25, 2382-2400.

Rose, K. (2016). Examining organizational citizenship behavior in the context of human resource development: An integrative review of the literature. Human Resource Development Review, 15, 295-316.

Russo, M., Guo, L., and Baruch, Y. (2014). Work attitudes, career success and health: Evidence from China. Journal of Vocational Behavior, 84, 248-258.

Sobel, M.E. (1982). Asymptotic confidence intervals for indirect effects in structural equation models. In Sociological Methodology, S. Leinhardt, ed. Washington, DC: American Sociological Association, 290-312.

Son, S.J., and Kim, D.-Y. (2016). The role of perceived management support and trust in mentors on protégés' organizational citizenship behavior. Asia Pacific Journal of Human Resources, 54, 481-497. 
Takeuchi, R., Way, S.A., and Tian, A.W. (2018). Cross-level effects of support climate: Main and moderating roles. Human Resource Management, 57, 1205-1218.

Thomas, C.H., and Lankau, M.J. (2009). Preventing burnout: the effects of LMX and mentoring on socialization, role stress, and burnout. Human Resource Management, 48, 417-432.

Uppal, N. (2017). Uncovering curvilinearity in the organizational tenure-job performance relationship: A moderated mediation model of continuance commitment and motivational job characteristics. Personnel Review, 46, 1552-1570.

Veitch, R.W.D., and Cooper.-Thomas, H.D. (2009). Tit for tat? Predictors of temporary agency workers' commitments. Asia Pacific Journal of Human Resources, 47, 318-337.

Wang, Q., Bowling, N.A., Tian, Q.-T., Alarcon, G.M., and Kwan, H.K. (2018). Workplace Harassment Intensity and Revenge: Mediation and Moderation Effects. Journal of Business Ethics, 151, 213-234.

Wang, Y. (2015). Examining organizational citizenship behavior of Japanese employees: a multidimensional analysis of the relationship to organizational commitment. International Journal of Human Resource Management, 26, 425-444.

Werner, J.M. (2000). Implications of OCB and contextual performance for human resource management. Human Resource Management Review, 10, 3-24.

Williams, L.J., and Anderson, S.E. (1991). Job satisfaction and organizational commitment as predictors of organizational citizenship and in-role behaviors. Journal of Management, 17, $601-617$.

Wu, X., Kwan, H.K., Wu, L.-Z., and Ma, J. (2018). The effect of workplace negative gossip on employee proactive behavior in China: The moderating role of traditionality. Journal of Business Ethics, 148, 801-815.

Xie, J.L., and Johns, G. (1995). Job scope and stress: Can job scope be too high? Academy of Management Journal, 38, 1288-1309.

Yi, J., Kwan, H.K., Hu, Y.-L., and Chen, S. (2017). Revenge exacerbates the effects of interpersonal problems on mentors' emotional exhaustion and work-family conflict: A selfdefeating perspective. Human Resource Management, 56, 851-866.

Zhan, X., Li, Z., and Luo, W. (2018). An identification-based model of workplace incivility and employee creativity: evidence from China. Asia Pacific Journal of Human Resources, https://doi.org/10.1111/1744-7941.12204 
Figure 1. Conceptual model

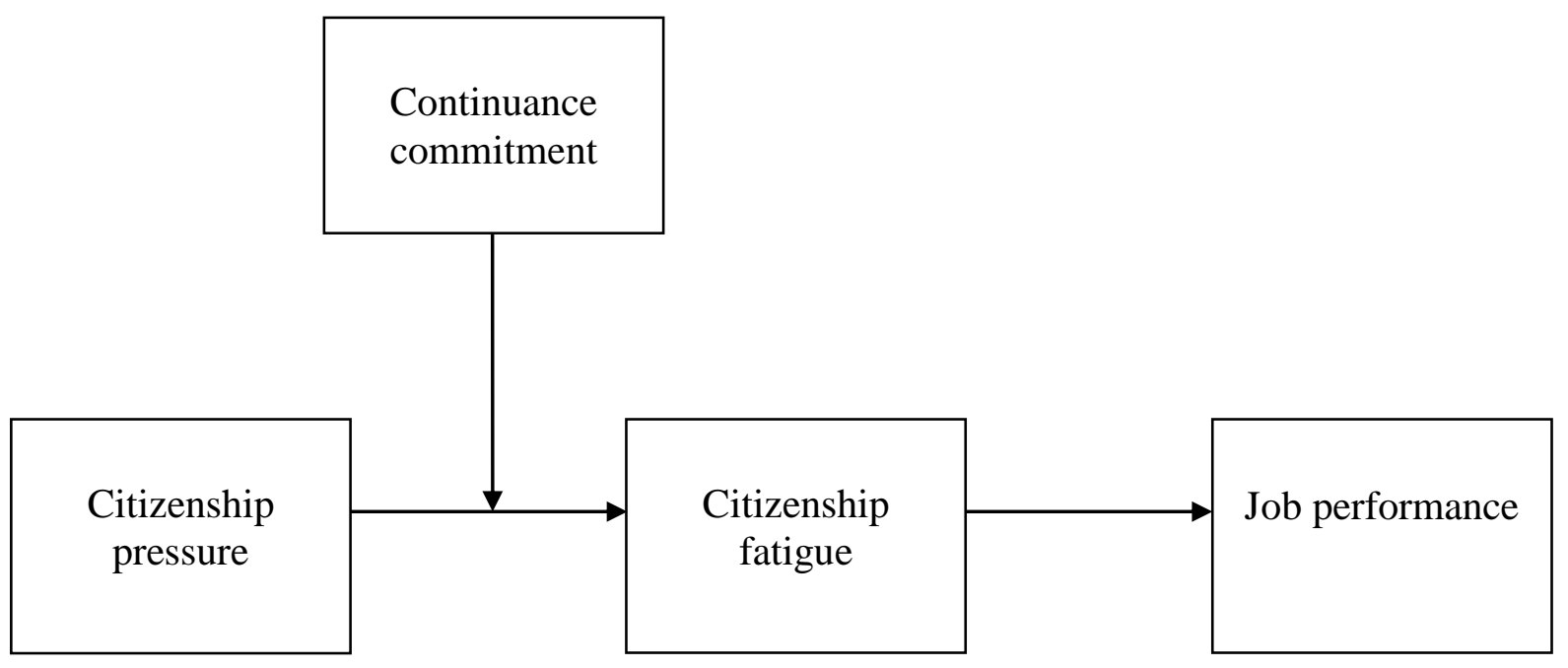


Figure 2: Moderating effect of continuance commitment on the relationship between citizenship pressure and citizenship fatigue

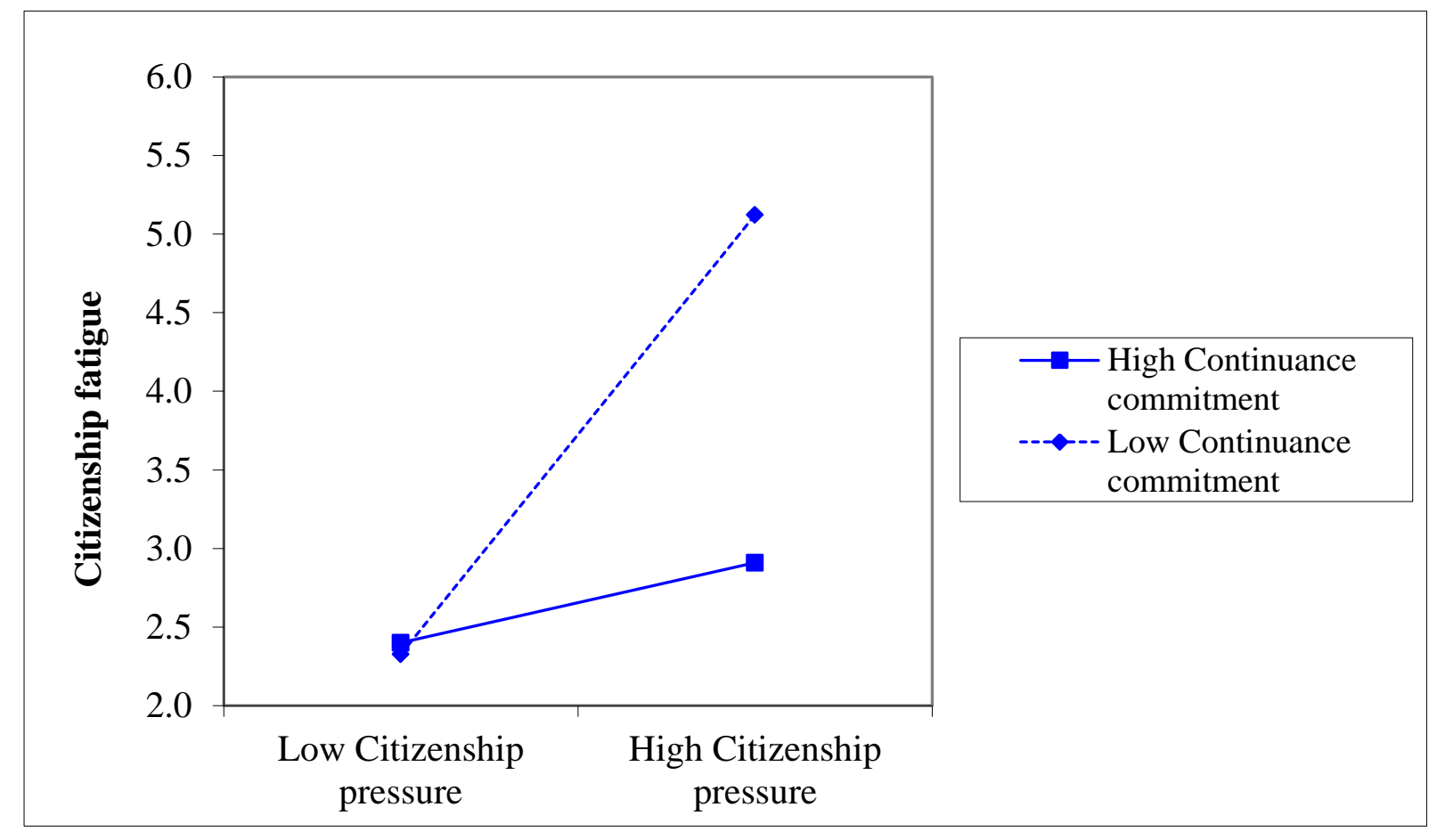




\begin{tabular}{|c|c|c|}
\hline & Loading & t-Value \\
\hline \multicolumn{3}{|l|}{ Citizenship pressure $(\alpha=.90 ; \mathrm{CR}=0.89 ; \mathrm{AVE}=0.51)$} \\
\hline $\begin{array}{l}\text { I feel a lot of pressure to go the extra mile by doing a lot of things that, } \\
\text { technically, I don't have to do. }\end{array}$ & .848 & $12.35 * * *$ \\
\hline $\begin{array}{l}\text { In this organization, the people who are seen as "team players" are the ones who } \\
\text { do significantly more than what is technically required of them. }\end{array}$ & .680 & $9.972 * * *$ \\
\hline $\begin{array}{l}\text { There is a lot of pressure to take on additional responsibilities and volunteer for } \\
\text { extra assignments in this organization. }\end{array}$ & .740 & $1.822 * * *$ \\
\hline $\begin{array}{l}\text { Simply doing your formally-prescribed job duties is not enough to be seen as a } \\
\text { good employee in this organization. }\end{array}$ & .748 & $1.952 * * *$ \\
\hline $\begin{array}{l}\text { My co-workers often go "above and beyond" the call of duty, and there is a lot of } \\
\text { pressure for me to do so as well. }\end{array}$ & .775 & $11.338 * * *$ \\
\hline $\begin{array}{l}\text { Management expects employees to "voluntarily" take on extra duties and } \\
\text { responsibilities that aren't technically required as a part of their job. }\end{array}$ & .685 & $1.029 * * *$ \\
\hline $\begin{array}{l}\text { Just doing your job these days is not enough - there is a lot of pressure to go } \\
\text { above and beyond the bare minimum. }\end{array}$ & .481 & $7.091 * * *$ \\
\hline $\begin{array}{l}\text { I feel a lot of pressure to work beyond my formally-prescribed duties for the } \\
\text { good of the organization. }\end{array}$ & $.706^{\mathrm{a}}$ & -- \\
\hline \multicolumn{3}{|l|}{ Citizenship fatigue $(\alpha=.91 ; \mathrm{CR}=0.91 ; \mathrm{AVE}=0.60)$} \\
\hline $\begin{array}{l}\text { Because of going the extra mile for my organization, I feel "on edge" about } \\
\text { various things. }\end{array}$ & .740 & $11.343 * * *$ \\
\hline I feel worn out because I go beyond the call of duty for my organization. & .831 & $12.821 * * *$ \\
\hline Doing so much for my organization leaves me mentally or physically exhausted. & .775 & $11.904 * * *$ \\
\hline I often lack energy because I go beyond my job duties at work. & .767 & $11.785 * * *$ \\
\hline I am tired of going beyond the call of duty for my organization. & .806 & $12.409 * * *$ \\
\hline $\begin{array}{l}\text { Volunteering to take on extra tasks and assignments at work has left me feeling } \\
\text { drained. }\end{array}$ & .753 & $11.542 * * *$ \\
\hline I am getting tired of being a team player in my organization. & $.734^{\mathrm{a}}$ & -- \\
\hline
\end{tabular}

Continuance commitment $(\alpha=.86 ; \mathrm{CR}=0.86 ; \mathrm{AVE}=0.44)$

I am not afraid of what might happen if I quit my job without having another one $\quad .440^{\text {a }} \quad$-lined up (reverse coded).

It would be very hard for me to leave my company right now, even if I wanted to. $\quad .658 \quad 6.162 * * *$

Too much in my life would be disrupted if I decided I wanted to leave my $\quad \begin{array}{lll}738 & 6.440^{* * * *}\end{array}$ company now.

$\begin{array}{llll}\text { It wouldn't be too costly for me to leave my company now (reverse coded). } & .679 & 6.239^{* * *}\end{array}$

Right now, staying with my company is a matter of necessity as much as desire. $\quad \begin{array}{lll}.562 & 5.735^{* * *}\end{array}$

I feel that I have too few options to consider leaving this company. $\quad .696 \quad 6.300^{* * *}$

One of the few serious consequences of leaving this company would be the $\quad \begin{array}{lll}.750 & 6.475^{* * * *}\end{array}$ scarcity of available alternatives.

I continue to work for this company because another company may not match the $\quad .705 \quad 6.333^{* * *}$

benefits I have now.

Job performance $(\alpha=.79 ; \mathrm{CR}=0.79 ; \mathrm{AVE}=0.36)$

This employee adequately completes assigned duties.

This employee fulfills responsibilities specified in job description. .68

This employee performs task that are expected of him/her.

This employee meets formal performance requirements of the job. 697

This employee engages in activities that will directly affect his/her performance $\quad .468 \quad 6.424 * * *$ evaluation.

This employee neglects aspects of the job he/she is obligated to perform (reverse $\quad .460 \quad 6.326^{* * *}$ coded).

This employee fails to perform essential duties (reverse coded).

${ }^{a}$ Initial loading was fixed to 1 , to set the scale of the construct.

Notes: $\alpha=$ Cronbach's alpha; $\mathrm{CR}=$ composite reliability; $\mathrm{AVE}=$ average variance extracted $* * * p<.001$. 
Table 2. Correlations and descriptive statistics

\begin{tabular}{lccccccc}
\hline & $\mathbf{1}$ & $\mathbf{2}$ & $\mathbf{3}$ & $\mathbf{4}$ & $\mathbf{5}$ & $\mathbf{6}$ & $\mathbf{7}$ \\
\hline 1. Citizenship pressure & & & & & & & \\
2. Citizenship fatigue & $.631^{* *}$ & & & & & & \\
3. Continuance commitment & $.466^{* *}$ & -.052 & & & & & \\
4. Job performance & $.146^{*}$ & -.122 & $.272^{* *}$ & & & & \\
5. Gender (1 = female) & -.061 & .044 & .075 & -.038 & & & \\
6. Age & $.136^{*}$ & .124 & .030 & .034 & .059 & & \\
7. Education (1 =masters) & .008 & .090 & -.100 & .013 & $.152^{*}$ & .037 & \\
8. Job level & .049 & .007 & $.232^{* *}$ & -.116 & .001 & -.059 & .013 \\
\hline \multicolumn{1}{c}{$\quad$ Mean } & 3.976 & 3.476 & 3.469 & 4.084 & .222 & 34.866 & .444 \\
\hline
\end{tabular}

Notes: $\mathrm{n}=239$.

$* p<.05 ; * * p<.01$. 
Table 3. Process results for individual paths

\begin{tabular}{|c|c|c|}
\hline & Citizenship fatigue & Job performance \\
\hline Gender $(1=$ female $)$ & $.165 *$ & -.007 \\
\hline Age & .001 & .001 \\
\hline Education $(1=$ masters $)$ & .028 & .041 \\
\hline Job level & $.083^{+}$ & $-.079 *$ \\
\hline Citizenship pressure & $.826^{* * *}$ & $.254 * * *$ \\
\hline Continuance commitment & $-.535 * * *$ & \\
\hline $\begin{array}{l}\text { Citizenship pressure } \times \\
\text { Continuance commitment }\end{array}$ & $-.571 * * *$ & \\
\hline Citizenship fatigue & & $-.208 * * *$ \\
\hline 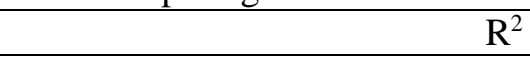 & .637 & .117 \\
\hline
\end{tabular}

Notes: $\mathrm{n}=239$.

$* p<.05 ; * * p<.01 ; * * * p<.001$. 
Table 4. Conditional indirect effects and index of moderated mediation

\begin{tabular}{lcccc}
\hline $\begin{array}{l}\text { Continuance } \\
\text { Commitment }\end{array}$ & Effect & Bootstrap SE & Bootstrap LLCI & Bootstrap ULCI \\
\hline-1 SD & -.252 & .051 & -.355 & -.157 \\
Mean & -.169 & .034 & -.237 & -.104 \\
$+1 \mathrm{SD}$ & -.079 & .029 & -.136 & -.024 \\
Index & .119 & .033 & .066 & .195 \\
\hline
\end{tabular}

Notes: $\mathrm{n}=239$; $\mathrm{SE}=$ standard error; $\mathrm{LLCI}=$ lower limit confidence interval; ULCI = upper limit confidence interval 